\title{
The Principles of Biomedical Scientific Writing: Introduction
}

\author{
Zahra Bahadoran ${ }^{1}$, Sajad Jeddi ${ }^{2}$, Parvin Mirmiran ${ }^{1}$ and Asghar Ghasemi ${ }^{2,}{ }^{*}$ \\ ${ }^{1}$ Nutrition and Endocrine Research Center, Research Institute for Endocrine Sciences, Shahid Beheshti University of Medical Sciences, Tehran, Iran \\ ${ }^{2}$ Endocrine Physiology Research Center, Research Institute for Endocrine Sciences, Shahid Beheshti University of Medical Sciences, Tehran, Iran \\ "Corresponding author: Endocrine Physiology Research Center, Research Institute for Endocrine Sciences, Shahid Beheshti University of Medical Sciences, Tehran, Iran. Email: \\ ghasemi@endocrine.ac.ir
}

Received 2018 September 30; Revised 2018 October 21; Accepted 2018 October 22.

\begin{abstract}
A well-written introduction of a scientific paper provides relevant background knowledge to convince the readers about the rationale, importance, and novelty of the research. The introduction should inform the readers about the "problem", "existing solutions", and "main limitations or gaps of knowledge". The authors' hypothesis and methodological approach used to examine the research hypothesis should also be stated. After reading a good introduction, readers should be guided through "a general context" to "a specific area" and "a research question". Incomplete, inaccurate, or outdated reviews of the literature are the more common pitfalls of an introduction that may lead to rejection. This review focuses on the principles of writing the introduction of an article and provides a quick look at the essential points that should be considered for writing an optimal introduction.
\end{abstract}

Keywords: Introduction, Writing Scientific Papers, Medical Scientific Journals

\section{Introduction}

Writing scientific papers is currently the most accepted outlet of research dissemination and scientific contribution. A scientific paper is structured by four main sections according to IMRAD (Introduction, Methods, Results, and Discussion) style (1).

To quote Plato, the Greek philosopher, "the beginning is half of the whole", and the introduction is probably one of the most difficult sections in writing a paper (2). For writing introduction of a scientific paper, a "deductive approach" is generally used; deduction is the reasoning used to apply general theories and principles to reach specific consequences or hypotheses (3).

The initial impression of readers about writing style, the overall quality of research, validity of its findings, and the conclusion is strongly influenced by the introduction (4). A poor introduction misleads the readers about the content of the paper, possibly discouraging them from reading the subsequent sections; a well-written introduction, however, convinces the reader about the research $\operatorname{logic}(4,5)$. A good introduction is hence the main challenge faced by authors when drafting a research manuscript (2).

Historically, writing an introduction as an independent section of a research paper was underscored in the 1980 (6). Studies available on scientific writing provide ev- idence emphasizing the complexity of the compositional process of writing an introduction; these studies concluded that "introduction is not just wrestling with words to fit the facts, but it is also strongly modulated by perceptions of the anticipated reactions of peer-colleagues" (6).

Although there is no single correct way to organize different components of a research paper (7), scientific writing is an experimental science (7), and several guides have been developed to improve the quality of research disseminations (8-11). Typically, an introduction contains a summary of relevant literature and background knowledge, highlights the gap of knowledge, states the research question or hypothesis, and describes the methodological approach used to fill in the gap and respond to the question (12-14). Some believe that introduction can be a major context for debate about research methodology (6).

This review focuses on the principles of writing the introduction section and provides a quick look at the main points that must be considered for writing a good introduction.

\section{Functions of the Introduction}

The introduction of a scientific paper may be described as the gate to a city (5). It may also resemble a mental road map that should elucidate "the known", "the unknown", and "the new knowledge added by findings of the current 
study" (4); it presents the background knowledge to convince the readers of the importance of data added to that available in the field (15); in addition, the introduction sets the scene for readers (16) and paves the way for what is to follow (17). The introduction should be tailored to the journal to which the manuscript is being submitted (18). It has two functions, to be informative enough for understanding the paper and to evoke the reader's interest $(19,20)$. An introduction should serve as a hook, informing the readers of the question they should expect the paper to address (7). "A good introduction will sell the study to editors, reviewers, and readers" $(18,21)$.

\section{Common Models of Writing an Introduction}

A historical overview of scientific writing shows that several models have been proposed overtime on how to organize the introduction of a research paper. One of the most common approaches is the "problem-solving model" developed in 1979; according to this model, a series of subcontexts including "goal", "current capacity", "problem", "solution", and "criteria for evaluation" have been described (6). The structure of this model could vary across disciplines $(22,23)$.

Another popular model proposed is "creating a research space", which mainly focuses on "the dark side" of the issue; this model, is usually known as CARS (create-aresearch-space) model and follows three moves including establishing a territory (the situation), establishing a niche (the problem), and occupying a niche (the solution) (24, 25). This model can be modified to a four-move model by expanding move 3 to include a "concluding step" when it is required to explain the structure of remaining parts of the paper $(6,25)$.

\section{A Typical Model of Introduction}

In this paper, we focused on a typical model of introduction commonly used in biomedical papers. As shown in Figure 1, the form of introduction is a funnel or an inverted pyramid, from large to small or broad to narrow (7, $16,19,26)$. The largest part of the funnel at the top describes the general context/topic and the importance of the study; the funnel then narrows down to the gap of knowledge, and ends with the authors' hypothesis or aim of the study and the methodological approach used to examine the research hypothesis $(18,26)$. In fact, introduction presents research ideas flowing from general to specific (27). As given below, in hypothesis-testing papers, the introduction usually consists of $2-3$ (28) and sometimes 4 paragraphs (16),

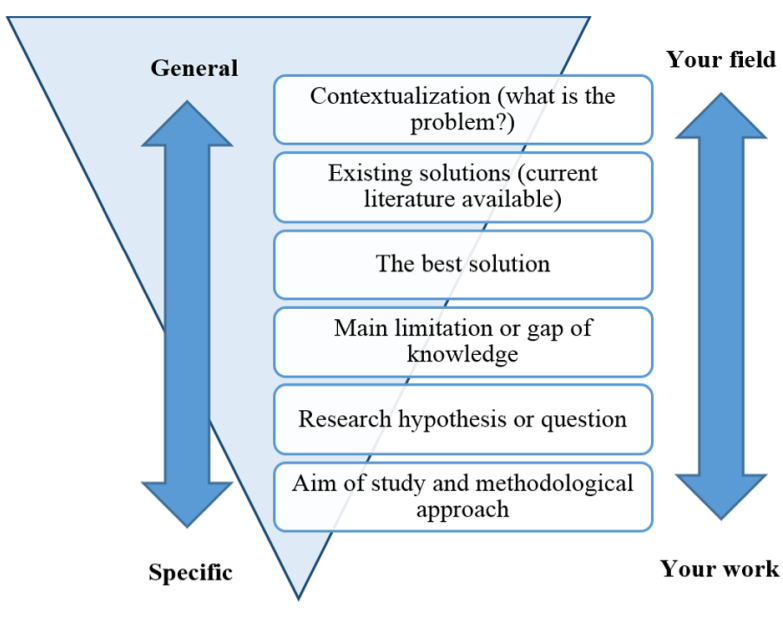

Figure 1. Sequential structure of a typical introduction

including the known, the unknown (knowledge gap), hypothesis/question or specific topic, and sometimes the approach $(16,19)$. Some authors end the introduction with essential findings of the paper (29). It has, however, been argued that the introduction should not include results or conclusion from the work being reported $(2,16,20)$, as readers would then lose their interest in reading the rest of the manuscript (2). The introduction may also be expanded by including some uncommon parts like "future implications of the work" (30).

\subsection{The Known}

In this section, a brief summary of background information is provided to present the general topic of the paper (20). This section should arouse and build the audience's attention and interest in the hypothesis/question or specific topic (29). This part may be considered the same as move 1 of the CARS model and includes "claiming importance", "making topic generalizations", and "reviewing items of previous research" $(22,24)$.

Besides the different roles proposed for citation, its primary motive is believed to be "perceived relevance" (31). It is important that the review of literature be complete, fair, balanced (29), to the point (19), and directly related to the study (16); it should not be too long or contain a very detailed review of literature $(7,28)$ or a complete history of the field (9). Depending on the audience (16), authors should include background information that they think readers need for following the rest of the paper (16).

Contrary to the current view that the introduction should be short and act as a prelude to the manuscript itself, another opinion, however, suggests this section provides a complete introduction to the subject (32). Sweep- 
ing generalizations (i.e., applying a general rule to a specific situation) should be avoided in the first (the opening) sentence of the introduction (8). The first three sentences of the first paragraph should present the issue that will be addressed by the paper (8). If the general topic be presented in the very first word of a very short sentence, the reader is able to immediately focus on and understand the issue (30).

\subsection{The Unknown/Gap of Knowledge}

The importance and novelty of the work should be stated in the introduction (19). This section describes the gaps in our present understanding of the field and why it is necessary that these gaps in data be filled (29). In this section, the author should present limitations of prior studies, needed (but currently unavailable) information, or an unsolved problem and highlight the importance of the missing pieces of the puzzle (16). This section provides information to justify the aim of the study, that is, it provides rationale for the readers to convince them $(8,20)$; however, one-sided or biased views of controversial issues should be avoided (33).

The unknown section of the introduction is similar to "establishing a niche" and includes "counter-claiming" and "indicating a gap" $(6,25)$. To develop a "counterclaiming" statement, the author needs to mention an opposing viewpoint or perspective or highlight a gap or limitation in current literature (24). "Counter-claiming" sentences are usually distinguished by a specific terminology, including albeit, although, but, howbeit, however, nevertheless, notwithstanding, unfortunately, whereas, and yet (24). This step toward or "continuing a tradition" part (6, 25 ) is an extension of prior research to expand upon or clarify a research problem (24), and the connection is commonly initiated with the following terms: "hence," "therefore," "consequently," or "thus" (24). An alternative approach for "counter-claiming" within the context of prior research is giving a "new perspective" without challenging the validity of previous research or highlighting their limitations (24).

Pitfalls in this section include missing an important paper and overstating the novelty of the study (29).

\subsection{Rationale of Research/Hypothesis/Question}

Defining the rationale of research is the most critical mission of the introduction section, where the author should tell the reader why the research is biologically meaningful (34). In stating the rationale of the study, an author should clarify that the study is the next logical step in a line of investigations, addressing the limitations of previous works (8). This section corresponds to "occupying the niche" in the CARS model (6), where contribution of the research in the development of "novel" knowledge is stated in contrast to prior research on the topic (24). The question/hypothesis, something that is not yet proven (35), is placed at the tip of the inverted cone/pyramid (16), and it is usually last sentence of the last paragraph in the introduction that presents the specific topic, which is "What was done in your paper?" $(7,8,19)$.

The main and secondary objectives should be clear and preferably comprise no more than two sentences (20). The question should be clearly stated as the most common reason for rejection of a manuscript is the inability to do this (8); it would be a bad start that reviewers/readers cannot grasp the research question of the paper (36).

\section{Writing Tips}

\subsection{The Length}

The introduction should be generally short $(7,37)$ and not exceed one double-spaced typed page (37), approximately 250 - 300 words are typically sufficient and sometimes it may be longer (500 - 600 words) $(19,38)$; however, depending on the audience and type of paper, the length of the introduction could vary (20); if it is more than twothirds the length of the results section, it is probably too long (9). It has been recommended that the introduction should be no more than $10 \%$ to $15 \%$ of total manuscript excluding abstract and references $(18,26)$. A long introduction may be used to compensate for the limited data given about the actual research, a pitfall that peer-reviewers are aware of (30).

\subsection{Sentence and Paragraph}

In a scientific paper, each paragraph should contain a single main idea $(7,39)$ that stands alone and is very clear (7). The first sentence of a paragraph should tell the reader what to expect to get out of the paragraph (7). Flow is a critical element in paragraph structure, that is to say, every sentence should arise logically from the sentence before it and transition logically into the next sentence (7). It is suggested that length of a sentence in a scientific text should not exceed 25 - 30 words; maximum three to four 30-word sentences are allowed in a paper (40). The ideal size for a paragraph is 3 - 4 sentences (maximum five sentences) (39) or 75 -150 words (ideally not exceeding 150 words)(30). The maximum length of a paragraph in a well-written paper should not exceed 15 lines (30).

To test readability of a paragraph or passage, the Gunning Fog scoring formula may be helpful. This index helps the author to write clearly and simply. Fog score is typically 
between 0 and 20 and estimates the years of formal education the reader requires to understand the text on the first reading ( 5 , is very easy; 6 is easy to read; 14 is difficult; 16 is very difficult) (41, 42). Fog score is calculated as follow:

$0.4\left[\left(\frac{\text { total words }}{\text { total sentences }}\right)+100\left(\frac{\text { complex words }}{\text { total words }}\right)\right]$

Where a complex word is defined as a word containing three or more syllables (43). An online tool that calculates the Gunning Fog Index is available at http://gunning-fogindex.com/index.html.

\subsection{Tense}

Using the correct verb tense in scientific writing enables authors to manage time and establish a logical relation or "time framework" within different parts of a paper (44). Two tenses are mostly used in scientific writing, namely the present and the past $(18,45)$; "present tense" is used for established general knowledge (general truths) and "past tense" for the results that you are currently reporting $(11,39,45)$. Some authors believe that "present tense" better describes most observations in a scientific paper $(5,7)$. To manage the time framework of the introduction, a transitional verb tense from "present simple" at the beginning (to describe general background) to "present perfect" (describing the problem over time), and again "present simple" at the end of introduction (to state the hypothesis and approach) is commonly recommended (30).

Although a review of the literature may recommend several tenses, using "present simple" or "present perfect" is more common (46); the use of "present tense" to refer to the existing research indicates that the authors believe the findings of an older research are still true and relevant (44). The "present perfect tense" may be adopted when authors communicate "currency" (being current), in both positive (asserting that previous studies have established a firm research foundation) and negative (asserting that not enough relevant or valid work has yet been done) forms (44).

As seen in Table 1, much of the introduction emphasizes on previously established knowledge, hence using the present tense $(11,37)$. If you give the author's name nonparenthetically, present or past tense could be used for the verb that is linked to the author; however, scientific work itself is given in the present tense; for instance, Smith (1975) showed that streptomycin inhibits growth of the organism (11).

\subsection{Citation}

Reference section is a vital component of papers (51). Peer-reviewed articles are preferred by scientific journals
(51). Be cautious never to cite a reference that you have not read (51) and be sure to cite the source of the original document (18). The number of references in the introduction should be kept to a minimum (19) according to the International Committee of Medical Journal Editors (http://icmje.org). Only directly pertinent references should be selected, but do not miss important previous works $(9,20)$. A common error in the writing of an introduction is the struggle to review all evidence available on the topic, which confuses the readers and often buries the aim of the study in additional information $(26,52)$. If there are many references, select the first, the most important, the most elegant, the most pertinent, and the most recent ones $(18,19)$. References should be selected from updated papers with higher impact factors (5). In addition, select original rather than review articles $(2,53)$, as this is what most editors/reviewers expect (18). In the presence of newer references, older ones are usually used if considered as being an influential work (16).

Unnecessary overlap of introduction and discussion is a problem for both sections, therefore, it has been strongly recommended to cite the references where it makes most sense (16). No reference needs to be made for accepted facts such as double-helical structure of DNA(9). There is usually no need to list standard text books as references and if this has been done, specify the place in the book (32). Some authors believe that referring to papers using author names should be avoided, as it slows the pace of writing (8).

\section{Common Pitfalls in Writing Introduction}

The most common pitfalls that occur during writing the introduction include: (1) Providing too much general information, (2) going into details of previous studies, (3) containing too many citations, (4) criticizing recent studies extensively, (5) presenting the conclusion of the study, except for studies where the format requires this, (6) having inconsistency with other sections of the manuscript, (7) including overlapping information with the discussion section, and (8) not reporting most relevant papers (2). In Table 2, most do's and don'ts for writing a good introduction are summarized; examples of the principles for writing an introduction for a scientific paper can be found in the literature $(16,19)$.

\section{Conclusion}

The introduction of scientific original papers should be short but informative. Briefly, the first part of a wellwritten introduction is expected to contain the most important concisely cited references, focused on the research 


\begin{tabular}{|c|c|c|}
\hline & Tense & Examples \\
\hline $\begin{array}{l}\text { To begin the introduction in order to } \\
\text { describe the general background context, } \\
\text { i.e. what is known already }\end{array}$ & Present simple & $\begin{array}{l}\text { Zinc, an essential dietary constituent, is a } \\
\text { co-factor of antioxidant enzymes ( } 47)\end{array}$ \\
\hline $\begin{array}{l}\text { To show how the problem has been } \\
\text { approached from the past until the present } \\
\text { day }\end{array}$ & Present perfect & $\begin{array}{l}\text { 1- Lower plasma zinc concentrations have been } \\
\text { reported in obese subjects (47); } 2 \text { - A direct } \\
\text { correlation has been observed between zinc } \\
\text { intake and incidence of chronic hypertensive } \\
\text { diseases (47) }\end{array}$ \\
\hline $\begin{array}{l}\text { To end the introduction, the authors present } \\
\text { what they will do in the remaining sections } \\
\text { of their paper (question/hypothesis) }\end{array}$ & Present simple/Past simple & $\begin{array}{l}\text { 1- The goal of this study is to provide ....(48); } 2 \text { - } \\
\text { We hypothesized that...(16); } 3 \text { - We tested the } \\
\text { hypothesis that ....(16); } 4 \text { - The research } \\
\text { presented here aimed to ....(49); } 5 \text {-We } \\
\text { examine....(50) }\end{array}$ \\
\hline \multicolumn{3}{|l|}{ Table 2. Do's and Don'ts of Writing a Good Introduction } \\
\hline & & References \\
\hline \multicolumn{3}{|l|}{ Do's } \\
\hline 1. Be short, clear, and focused & & $(19,20,32)$ \\
\hline \multicolumn{2}{|c|}{ 2. Include precise question follows inevitably from the previous statements } & $(19,20)$ \\
\hline \multicolumn{2}{|l|}{ 3. Specify animal or human population } & (19) \\
\hline \multicolumn{2}{|l|}{ 4. Emphasize that the work is new } & $(19)$ \\
\hline \multicolumn{2}{|l|}{ 5. Underscore the importance of the work } & (19) \\
\hline \multicolumn{2}{|l|}{ 6. State if the study is retrospective } & $(19)$ \\
\hline \multicolumn{2}{|c|}{ 7. Elaborate on background where the question is originated } & (19) \\
\hline \multicolumn{2}{|l|}{ 8. Include a funnel organization } & $(7,16,19)$ \\
\hline \multicolumn{3}{|l|}{ Don'ts } \\
\hline \multicolumn{2}{|c|}{ 1. Include the answer to the question, results, and implications } & $(7,19,20)$ \\
\hline \multicolumn{2}{|l|}{ 2. Include a large number of references } & $(19)$ \\
\hline \multicolumn{2}{|c|}{ 3. Present one-sided biased views of controversial issues } & (33) \\
\hline \multicolumn{2}{|l|}{ 4. Cite out-of-date articles } & (33) \\
\hline \multicolumn{2}{|l|}{ 5. Omit important references } & $(20,33)$ \\
\hline \multicolumn{2}{|l|}{ 6. Include jargons } & $(7,54)$ \\
\hline
\end{tabular}

problem. In the second part, the problem and existing solutions or current limitations should be elaborated, and the last paragraph should describe the rationale for the research and the main research purpose. The introduction is suggested be concluded with a brief paragraph that describes the organization of the rest of the paper. Overall, a good introduction should convince the readers that the study is important in the context of what is already known.

\section{Acknowledgments}

The authors wish to acknowledge Ms Niloofar Shiva for critical editing of English grammar and syntax of the manuscript. 


\section{References}

1. Peh WC, Ng KH. Basic structure and types of scientific papers. Singapore Med J. 2008;49(7):522-5. [PubMed: 18695858].

2. Bavdekar SB. Writing introduction: Laying the foundations of a research paper. J Assoc Physicians India. 2015;63(7):44-6. [PubMed: 26731827].

3. Heit E, Rotello CM. Relations between inductive reasoning and deductive reasoning. J Exp Psychol Learn Mem Cogn. 2010;36(3):805-12. doi: 10.1037/a0018784. [PubMed: 20438276].

4. University of Southern California. Organizing your social sciences research paper: 4 . the introduction. USC;201811 Aug. Available from: https: //libguides.usc.edu/writingguide.

5. Armagan A. How to write an introduction section of a scientific article? Turk J Urol. 2014;39(1):8-9. doi: 10.5152/tud.2013.046. [PubMed: 26328128]. [PubMed Central: PMC4548565].

6. Swales JM, Najjar H. The writing of research article introductions. Written Commun. 2016;4(2):175-91. doi: 10.1177/0741088387004002004.

7. Plaxco KW. The art of writing science. Protein Sci. 2010;19(12):22616. doi: 10.1002/pro.514. [PubMed: 20954234]. [PubMed Central: PMC3009394].

8. Kliewer MA. Writing it up: A step-by-step guide to publication for beginning investigators. AJR Am J Roentgenol. 2005;185(3):591-6. doi: 10.2214/ajr.185.3.01850591. [PubMed: 16120904].

9. Korner AM. Guide to publishing a scientific paper. London: Imprint Routledge; 2008.

10. Kotsis SV, Chung KC. A guide for writing in the scientific forum. Plast Reconstr Surg. 2010;126(5):1763-71. doi: 10.1097/PRS.0b013e3181ef8074. [PubMed: 21042135]. [PubMed Central: PMC3052777].

11. Matthews JR, Bowen JM, Matthews RW. Successful scientific writing: A step-by-step guide for the biological and medical sciences. 3rd ed. New York: Cambridge University Press; 2007.

12. Young P. Writing for publication. Nurse Educ Today. 1987;7(6):285-8. doi:10.1016/0260-6917(87)90130-4. [PubMed:3444435].

13. Sand-Jensen K. How to write consistently boring scientific literature. Oikos. 2007;116(5):723-7. doi: 10.1111/j.0030-1299.2007.15674.x.

14. Downey SM, Geraci SA. Manuscript development and publishing: A 5-step approach. Am J Med Sci. 2017;353(2):132-6. doi: 10.1016/j.amjms.2016.12.005. [PubMed: 28183413].

15. Wallwork A. Introduction. In: Wallwork A, editor. English for writing research papers. Springer; 2011. p.195-205. doi:10.1007/978-1-4419-79223 13.

16. Annesley TM. "It was a cold and rainy night": Set the scene with a good introduction. Clin Chem. 2010;56(5):708-13. doi: 10.1373/clinchem.2010.143628. [PubMed: 20207764].

17. Harmon JE, Gross AG. Introducing your problem. In: Harmon JE, Gross AG, editors. The craft of scientific communication. United States of America: University of Chicago Press; 2010. p. 3-18.

18. Cals JW, Kotz D. Effective writing and publishing scientific papers, part III: Introduction. J Clin Epidemiol. 2013;66(7):702. doi: 10.1016/j.jclinepi.2013.01.004. [PubMed: 23497856].

19. Zeiger M. Introduction. In: Zeiger M, editor. Essentials of writing biomedical research papers. 2nd ed. McGraw-Hill; 2000. p.107-27.

20. Peh WC, Ng KH. Writing the introduction. Singapore Med J. 2008;49(10):756-7. quiz758. [PubMed: 18946606].

21. Jha KN. How to write articles that get published. J Clin Diagn Res. 2014;8(9):XG01-3. doi: 10.7860/JCDR/2014/8107.4855. [PubMed: 25386508]. [PubMed Central: PMC4225960].

22. Samraj B. Introductions in research articles: Variations across disciplines. English Specif Purpos. 2002;21(1):1-17. doi: 10.1016/s08894906(00)00023-5.

23. Abdullah S. An analysis of cross-discipline research article introduction structures through a modified create-a-research-space (cars) model. EFL J. 2016;1(1):1. doi: 10.21462/eflj.vli1.1.

24. University of Southern California. Organizing your social sciences re- search paper: The C.A.R.S. model. USC; 201811 Aug. Available from: http //libguides.usc.edu/writingguide/CARS.

25. Swales JM. Introduction to the reissue. In: Swales JM, editor. Aspects of article introductions. Unites States of America: University of Michigan Press; 2011. p. 1-10.

26. Jirge PR. Preparing and publishing a scientific manuscript. J Hum Reprod Sci. 2017;10(1):3-9. doi: 10.4103/jhrs.JHRS_36_17. [PubMed: 28479749]. [PubMed Central: PMC5405644].

27. Paiva RP. How to write good scientific papers: A comprehensive guide. Tutorial. 2013. Available from: http://rppaiva.dei.uc.pt/publications/ Tutorials/goodPapers.pdf.

28. Van Way CW. Writing a scientific paper.Nutr Clin Pract. 2007;22(6):63640. doi: 10.1177/0115426507022006636. [PubMed:18042951].

29. Cetin S, Hackam DJ. An approach to the writing of a scientific manuscript. J Surg Res. 2005;128(2):165-7. doi 10.1016/j.jss.2005.07.002. [PubMed:16154592].

30. Wallwork A. Introduction. In: Wallwork A, editor. English for writing research papers. Springer; 2016. p. 249-64

31. Swales JM, Feak CB. Constructing a research paper II. In: Swales JM, Feak CB, editors. Academic writing for graduate students: Essential tasks and skills. Ann Arbor MI: University of Michigan Press; 2004. p. 327-78.

32. Thrower PA. Writing a scientific paper: II. Introduction and refer ences. Carbon. 2008;46(2):183-4. doi:10.1016/j.carbon.2008.01.010.

33. Streiner DL. A shortcut to rejection: How not to write the results section of a paper. Can J Psychiatry. 2007;52(6):385-9. doi: 10.1177/070674370705200608. [PubMed:17696025].

34. Harris M, Batzli J. Writing an introduction for a scientific paper University of Wisconsin-Madison; 201812 Aug. Available from: https://writing.wisc.edu/wac/writing-an-introduction-for-ascientific-paper/.

35. Bains W. How to write up a hypothesis: The good, the bad and the ugly Med Hypotheses. 2005;64(4):665-8. doi: 10.1016/j.mehy.2004.10.003. [PubMed: 15694680]

36. Chiswick M. Writing a research paper. Curr Paediatr. 2004;14(6):513-8. doi: 10.1016/j.cupe.2004.07.003.

37. Gustavii B. Introduction. In: Gustavii B, editor. How to write and illus trate a scientific paper. 2nd ed. Cambridge University Press; 2008. p 61-2. doi: 10.1017/cbo9780511808272.013.

38. Kallestinova ED. How to write your first research paper. Yale J Biol Med. 2011;84(3):181-90. [PubMed: 21966034]. [PubMed Central: PMC3178846].

39. Katz MJ. Scientific words, sentences, and paragraphs. In: Katz MJ, editor. From Research to Manuscript: A Guide to Scientific Writing. Springer; 2009. p. 5-11

40. Wallwork A. Breaking up long sentences. In: Wallwork A, editor. English for writing research papers. Springer; 2016. p. 249-64.

41. Gunning R. The fog index after twenty years. J Bus Commun. 2016;6(2):3-13. doi: 10.1177/002194366900600202.

42. Audisio RA, Stahel RA, Aapro MS, Costa A, Pandey M, Pavlidis N. Successful publishing: How to get your paper accepted. Surg Oncol. 2009;18(4):350-6. doi: 10.1016/j.suronc.2008.09.001. [PubMed 18849161].

43. Colmer R. Readability and the gunning fog index. readable.io; 2018 Available from: https://readable.io/blog/the-gunning-fog-index/.

44. The University of Melbourn. Using tenses in scientific writing. UM 201812 Aug. Available from: https://services.unimelb.edu.au/_data/ assets/pdf_file/0009/471294/Using_tenses_in_scientific_writing_ Update_051112.pdf.

45. Gustavii B. Comments on scientific language. In: Gustavii B, editor How to write and illustrate a scientific paper. 2 nd ed. Cambridge University Press; 2008. p. 3-14

46. Wallwork A. Review of the litrature. In: Wallwork A, editor. English for writing research papers. Springer; 2016. p. 249-64.

47. Ghasemi A, Zahediasl S, Hosseini-Esfahani F, Azizi F. Gender differences in the relationship between serum zinc concentration 
and metabolic syndrome. Ann Hum Biol. 2014;41(5):436-42. doi: 10.3109/03014460.2013.870228. [PubMed: 24588511].

48. Abbasi F, Okeke Q, Reaven GM. Evaluation of fasting plasma in sulin concentration as an estimate of insulin action in nondiabetic individuals: Comparison with the homeostasis model assessment of insulin resistance (HOMA-IR). Acta Diabetol. 2014;51(2):193-7. doi 10.1007/s00592-013-0461-2. [PubMed: 23420066].

49. Sheldrake R. Confidence as motivational expressions of interest, utility, and other influences: Exploring under-confidence and overconfidence in science students at secondary school. Int J Educ Res. 2016;76:50-65. doi:10.1016/j.ijer.2015.12.001.

50. de Freitas E, Sinclair N. The cognitive labour of mathematics dis/ability: Neurocognitive approaches to number sense. Int J Educ Res. 2016;79:222-30. doi:10.1016/j.ijer.2015.10.008.

51. Riordan L. Modern-day considerations for references in scientific writing. J Am Osteopath Assoc. 2012;112(8):567-9. [PubMed: 22904255].

52. Hoogenboom BJ, Manske RC. How to write a scientific article. Int J Sports Phys Ther. 2012;7(5):512-7. [PubMed: 23091783]. [PubMed Central: PMC3474301].

53. Cals JW, Kotz D. Effective writing and publishing scientific papers, part VIII: References. J Clin Epidemiol. 2013;66(11):1198. doi: 10.1016/j.jclinepi.2013.06.015. [PubMed: 24079642].

54. Rothman KJ. Writing for epidemiology. Epidemiology. 1998;9(3):333-7. doi: 10.1097/00001648-199805000-00019. [PubMed: 12296359]. 